\title{
An Assistive Technology Design Framework for ADHD
}

\author{
Tobias Sonne ${ }^{1}$, Paul Marshall ${ }^{2}$, Carsten Obel ${ }^{3}$, Per Hove Thomsen ${ }^{4}$, Kaj Grønbæk ${ }^{1}$ \\ ${ }^{1}$ Department of \\ ${ }^{2}$ UCL Interaction Center \\ ${ }^{3}$ Department of \\ ${ }^{4}$ Department of \\ Computer Science \\ University College \\ Aarhus, Denmark \\ London, London, WC1E \\ 6BT, UK \\ Public Health, \\ Clinical Medicine - Psychiatric \\ Aarhus University, \\ Denmark \\ Hospital for Children and \\ Adolescents, Aarhus \\ University, Denmark
}

\{tsonne, kgronbak\}@cs.au.dk, paul.marshall@ucl.ac.uk,co@au.dk, per.hove.thomsen@clin.au.dk

\begin{abstract}
In this paper, we present a design framework for ADHD assistive technologies that aims to give researchers grounding in the background research on the condition, to provide a lingua franca, and to highlight potential research directions for HCI researchers within assistive technology. The design framework couples ADHD patient challenge areas to technological opportunities and it provides a set of practical design strategies for developing successful assistive technologies for people with ADHD. The framework is based on empirical studies, ADHD research, and related work on assistive technologies. We map existing assistive technologies and potential new research efforts to the framework concepts. This way we show how it is used to support and advance the research and development of novel assistive technologies for the ADHD domain.
\end{abstract}

\section{Author Keywords}

Design; children; adults; ADHD; assistive technologies; interventions; design framework; mental disorders; health.

\section{ACM Classification Keywords}

H.5.m. Information interfaces and presentation (e.g., HCI): Miscellaneous;

\section{INTRODUCTION}

HCI researchers have recently explored and demonstrated the potential of using technology to assist and empower patients with a broad range of mental health conditions (e.g. (Fage et al., 2014; Hirano et al., 2010; Kientz et al., 2013; Milne et al., 2014)). However, to date there has been limited attention on the development of technologies to support people with Attention Deficit Hyperactivity Disorder (ADHD), despite ADHD being the most prevalent reported mental health diagnosis for children and teens (Perou et al., 2013). In comparison with other disorders like

Permission to make digital or hard copies of all or part of this work for personal or classroom use is granted without fee provided that copies are not made or distributed for profit or commercial advantage and that copies bear this notice and the full citation on the first page. Copyrights for components of this work owned by others than ACM must be honored. Abstracting with credit is permitted. To copy otherwise, or republish, to post on servers or to redistribute to lists, requires prior specific permission and/or a fee. Request permissions from Permissions@acm.org.

OzCHI '16, November 29 - December 2 2016, Launceston, TAS, Australia

Copyright (C) 2016 ACM 978-1-4503-3673-4/15/12 .. \$15.00

http://dx.doi.org/xx.xxxx/xxxxxxx.xxxxxxx. autism spectrum disorder (ASD) (Abdullah and Brereton, 2015; Cramer et al., 2011; Hirano et al., 2010; Kientz et al., 2013) and bipolar disorder (Bardram et al., 2013), there has been far less research on assistive technologies for the ADHD domain. Yet the potential long-term consequences of ADHD are many, including social and academic impairments (Massetti et al., 2008), low self-esteem (Wehmeier et al., 2010), and increased risk of criminal conviction (Dalsgaard et al., 2013). Important early research (e.g., Pina et al. (2014)|; Weisberg et al. (2014)) has primarily focused on technological exploration rather than on guidelines for designing assistive technologies for this domain.

In this paper, we seek to provide researchers within assistive technology and related HCI communities with a design framework for discussing and developing novel assistive technologies for people with ADHD. Our design framework is grounded in an analysis of the ADHD literature, related technology development for people with ADHD, as well as other conditions and lessons learned from our work within this field. The design framework comprises two parts: 1) two taxonomic dimensions: a technology dimension and an ADHD symptom dimension; and 2) A set of practical design strategies. For 1), the technology dimension introduces three approaches, which each relates to the functionality the assistive technology provides: 1. Manually Interacting with Information and Services (MIIS); 2. Automatically Executing Services (AES) based on in-situ analysis of contextual information, and 3. Capturing Contextual Data (CCD) for later retrieval. The ADHD dimension in the design framework spans five categories that all relate to how ADHD impacts the quality of life of people with ADHD (Faraone et al., 2015). From plotting related work into the design framework, we identify several unexplored opportunities for assistive technologies for the ADHD domain. We illustrate with existing systems and potential research efforts how the design framework can be used to advance existing technologies, and provide an example of how we have used the design framework in our own design process.

\section{BACKGROUND}

ADHD is a persistent neurodevelopmental disorder. It is the most prevalent mental health disorder in children and adolescents aged 3-17 (Perou et al., 2013), with a 
worldwide prevalence of approximately 5\% and affecting approximately $3 \%$ of adults (Faraone et al., 2015). ADHD is characterized by inattention, hyperactivity/impulsivity, or both, and thus has three presentations: 1. predominantly inattentive; 2. Predominantly hyperactive/impulsive; and 3. combined inattentive hyperactive/impulsive. The causes of ADHD are debated, and are outside the scope of this paper. However, as the heritability of ADHD is $70-80 \%$, genetics is considered to be an important factor (Biederman and Faraone, 2005; Faraone et al., 2015).

In the US and Australia, ADHD is diagnosed according to the Diagnostic and Statistical Manual, Fifth Edition (DSMV) (DSM-V, 2013), whereas in most of Europe, ADHD is diagnosed according to the International Classification of Diseases-10 (ICD-10) as a hyperkinetic disorder (HKD) (World Health Organization, 1992). The ICD-10 diagnostic criteria are more restrictive than those of the DSM-V, which has sometimes been misinterpreted as suggesting that ADHD is more common in the US (Biederman and Faraone, 2005).

Traditional ADHD treatments include prescribed medication and cognitive behavioral interventions. The National Institute of Health and Care Excellence ("Attention deficit hyperactivity disorder | introduction | Guidance and guidelines | NICE," 2015) suggest that parent-training and education should be used as the first options in treatment, and prescribed medication as a second option. Though medication is shown to significantly improve ADHD symptoms for some, there are potential downsides, including: 1) Side effects of medication like sleep problems (Storebø et al., 2015), stomach pains, dysphoria and growth delays (Faraone et al., 2015); 2) Treatment of symptoms rather than the underlying condition, such that when medication stops ADHD symptoms reappear; and 3) No significant improvement in academic achievement (Chacko et al., 2014). A 2015 meta review analyzing the effect of the most common drug (methylphenidate) in the treatment of ADHD found that it "may improve teacher-reported ADHD symptoms, teacher-reported general behavior, and parentreported quality of life among children and adolescents diagnosed with ADHD" (Storebø et al., 2015). However due to the low quality of the underpinning evidence, the magnitude of these effects cannot be certain (Storebø et al., 2015).

Behavioral therapy programs like the parent training program 'The Incredible Years' (Webster-Stratton and Jamila, 2003) have shown to reduce parent-reported ADHD symptoms. Most parent training programs include the following five core elements: 1) promoting play and a positive relationship; 2) giving praise and rewards for positive behavior; 3) providing clear rules and clear commands; 4) consistent and calm consequences for unwanted behavior; and 5) organizing the child's day to reduce the chances of tensions (National Collaborating Centre for Mental Health (Great Britain) and NCCMH, 2013).

\section{Common Challenges for People with ADHD}

In this section we document some of the challenges people with ADHD experience according to the three presentations of the ADHD diagnosis. However, it is important to remember that ADHD is a highly heterogeneous disorder and thus it manifests and affects people to varying degrees.

People with ADHD with a high degree of inattention are often described as "daydreamers". They commonly experience challenges in paying and sustaining attention as well as shifting attention between activities (DSM-V, 2013). Consequently, they often appear not to be listening, struggle to follow through on instructions, have difficulties organizing tasks, are easily distracted, and often lose things. Furthermore, they often avoid tasks that require continued concentration and can be forgetful (DSM-V, 2013).

People with hyperactive/impulsive presentation often struggle to control their actions, which can be misunderstood as them being rude or in children willfully disobedient (DSM-V, 2013). They often experience difficulties with activities like remaining seated, waiting in line or engaging in activities quietly. Children with ADHD often blurt out answers, run or climb in inappropriate situations and places, experience extreme restlessness, talk a lot, and intrude or interrupts others (DSM-V, 2013). People within the combined presentation (inattentive and hyperactive/impulsive) experience a combination of both of the above sets of challenges.

People with ADHD often also struggle with transitions between activities and with perceiving time (Sonne and Grønbæk, 2015). Furthermore, ADHD is associated with sleep problems: a meta-analysis found that children with ADHD had significantly higher bedtime resistance, sleep onset difficulties, night awakenings, difficulties with morning awakenings and sleep disordered breathing compared to children without ADHD (Cortese et al., 2009).

As a consequence of challenges caused by their disorder, children with ADHD typically experience issues in interacting with parents and teachers (Storebø et al., 2014). ADHD is also associated with impaired academic performance (Massetti et al., 2008), emotional dysregulation (Shaw et al., 2014), and to significantly affect children's quality of life: in one study, $70 \%$ of third graders with ADHD reported that they had no close friends (Wehmeier et al., 2010). In addition to issues caused as a consequence of the core deficits of $\mathrm{ADHD}$, further challenges may arise from comorbid disorders as more than $80 \%$ of people with ADHD have one additional psychiatric disorder, and more than $50 \%$ have two additional disorders (Wehmeier et al., 2010). 


\begin{tabular}{|c|c|c|c|}
\hline System & Type of System & Context & Target User Group \\
\hline MOBERO & $\begin{array}{c}\text { Manually interacting with information and } \\
\text { services }(M I I S)\end{array}$ & Home & Children + Parents \\
\hline TangiPlan & MIIS & Home & Children \\
\hline ChillFish & MIIS & Home/School & Children \\
\hline TimeTimer & MIIS & Home/School & Children + adults \\
\hline CogoLand & MIIS & Home & Children \\
\hline CogMed & MIIS & Home & Children \\
\hline ParentGuardian & $\begin{array}{l}\text { Automatically executed services based on in-situ } \\
\text { analysis of context information }(A E S)\end{array}$ & Home & Parents of children with ADHD \\
\hline $\begin{array}{c}\text { Smart } \\
\text { wristwatch }\end{array}$ & $A E S$ & School & Children \\
\hline SmartPen & $A E S$ & School & Children \\
\hline
\end{tabular}

Table 1: Overview of the limited related work on assistive technologies for the domain of ADHD.

Faraone et al. (Faraone et al., 2015) presented five general quality of life impairments associated with ADHD: 1. 'Social disability' relates to poor social skills, poor peer/family relationship, and parenting problems; 2. 'Academic and occupational failure' relates to e.g., underachievement, special education needs, and grade repetition in childhood and adolescence; and e.g., unemployment and lower socioeconomic status in adulthood; 3. 'Health problems and psychiatric co-morbidities' category relates to e.g., disruptive behavior, specific learning disabilities, executive dysfunction, and speech and language disorders; 4. 'Psychological dysfunction' relates to e.g., emotional dysregulation, lack of motivation, low self-esteem; and from adulthood suicidal ideation, suicide attempts, and suicide; and 5. 'Risky behaviors' relates to e.g., accidents, injuries, and unplanned pregnancies.

\section{RELATED WORK ON ASSISTIVE TECHNOLOGIES}

We now present related work on assistive technology for the ADHD domain grouped according the three technology approaches in our design framework (see Error! Reference source not found.).

\section{Existing MIIS Technologies}

MOBERO (Sonne et al., 2016b, 2016a), TangiPlan (Weisberg et al., 2014), ChillFish (Sonne and Jensen, 2016a), and TimeTimer ("Time Timer," 2016) are all examples of manually interacted with information and service (MIIS) systems that provide assistance in specific contexts. MOBERO is a smartphone system that assists children with ADHD and their families in establishing healthy morning and bedtime routines, by providing structure and rewards (Sonne et al., 2016b). Through a twoweek baseline period followed by a two-week intervention period, Sonne et al. found that use of MOBERO was associated with lower parental frustration levels during morning and bedtime routines and increased parent-rated child independence, based on daily assessments from parents during both baseline and intervention periods (Sonne et al., 2016b). Furthermore, through validated clinical questionnaires a $16.5 \%$ reduction in parent-rated ADHD core symptoms like an improvement in sleep quality was identified (Sonne et al., 2016b). Similar to MOBERO, TangiPlan is designed to assist children with ADHD to complete their morning routines (Weisberg et al., 2014). TangiPlan is only used by the child, and uses tangible connected objects to represent the morning activities the child has to complete. ChillFish (Sonne and Jensen, 2016a, 2016b) is different to MOBERO and TangiPlan as it does not provide assistance for a specific routine. Instead, it is a calming biofeedback game, where by breathing through a tangible LEGO fish the child controls a virtual puffer fish in a virtual underwater world (Sonne and Jensen, 2016a). The goal of ChillFish is to collect as many starfish as possible, which is achieved by performing a calming breathing exercise (Sonne and Jensen, 2016a). TimeTimer is a commercial product that is available in wristband, mobile phone app and physical device versions, which all assist the person in staying focused by visualizing the time remaining on a task. In addition to people with ADHD it is also claimed to be beneficial for others such as those with ASD.

CogoLand and CogMed are two other examples of MIIS systems, which in contrast to MOBERO, TangiPlan, ChillFish, and TimeTimer focus on training core ADHD deficits. Lim et al. (Lim et al., 2012) investigated the effect of the neurofeedback game CogoLand on children's ADHD symptoms. The gameplay is based on an avatar in a 3D world, which has to complete a race as fast as possible. The speed of the avatar is controlled by the child's level of concentration, which is measured using an electroencephalography (EEG) headband (Lim et al., 2012). 20 children with ADHD participated in an experiment that ran for 24 weeks, and eight weeks into the experiment the 
results showed a drop in ADHD symptoms (Lim et al., 2012). Similarly, Cogmed is a research based PC application that trains the child's working memory ("Cogmed Working Memory Training," 2015). Though working memory and neurofeedback interventions have shown promising results, the effect of these studies are inconsistent and often based on small populations making definitive conclusions hard to draw (Chacko et al., 2014).

\section{Existing AES Technologies}

When looking at related work within the AES category ParentGuardian (Pina et al., 2014) is maybe the best known example. ParentGuardian provides in situ parental behavioral therapy (PBT) cues for parents of children with ADHD, in order to support parents to better manage stressful situations. The ParentGuardian system uses changes in skin conductance, measured by an electro dermal activity wristband, to estimate the stress level of the parent. When a high level of stress is detected, the parent is prompted with a combined textual and visual reflective strategy on their smartphone and on a peripheral display to remind them to use PBT strategies (Pina et al., 2014). Pina et al. found that in situ cues could assist parents to remember to use the PBT strategies during moments high stress (Pina et al., 2014).

An example of an $A E S$ system for the school context can be found in the smart wristband prototype by McHugh et al. (McHugh et al., 2010) who investigated if a watch connected to a heart rate belt could assist children to avoid emotional outbursts in school. By analyzing sensor data from the heart rate belt, the system detects an approaching emotional outburst, and alerts the child to use self-calming techniques to prevent it. McHugh et al. found their system to be useful in assisting children to calm down without the need of help from parents or teachers (McHugh et al., 2010). Similarly, the Smart Pen prototype by DePrenger et al. (DePrenger et al., 2010) is designed to detect concentration lapses during reading in school and redirect the child's attention back to the reading task. Via an embedded 3-axis accelerometer and a machine-learning algorithm, the Smart Pen is able to recognize reading patterns. The Smart Pen discretely reminds children to resume reading by either lighting a small LED or vibrating.

More recently we have seen both CASTT (Sonne et al., 2015) and BlurtLine (Smit and Bakker, 2015) as examples of wearable $A E S$ systems. CASTT collects movement and physiological data and uses it to assist children with ADHD to regain attention in critical school situations. Development on CASTT is ongoing (Sonne et al., 2015), however preliminary evaluations in four different schools have been conducted with positive outcomes (Sonne et al., 2015). BlurtLine (Smit and Bakker, 2015) is also a wearable prototype system designed for children with ADHD to be used in school contexts. It relies on an interactive chest strap that monitors the wearer's breathing pattern to predict and prevent a child with ADHD from blurting (impulsive speaking behavior). When a forthcoming blurt is detected, BlurtLine alerts the child though tactile feedback. The ability to detect potential blurts was evaluated with adults in a controlled setting with positive results (Smit and Bakker, 2015). However, to date BlurtLine has only been evaluated with one child with ADHD in a school context.

Even though limited, the prior work show great promise for assistive technologies within the ADHD domain. However, existing research has focused on isolated systems, and does not provide directions for further research on how to design technology for the ADHD domain. In this paper, we present a design framework for ADHD assistive technologies that aims to give researchers grounding in the condition, to provide a lingua franca, and to highlight unexplored research directions. In addition, we also present practical design strategies for developing successful assistive technologies for people with ADHD.

\section{EXPLORING THE ADHD DOMAIN THROUGH DESIGNING AND EVALUATING PROTOTYPES}

Though four design projects we have conducted several empirical studies including: 1 . More than 50 hours (2.5 3.0 hours each week for 20 weeks) of experience working with and taking care of children with ADHD, while their parents received parent training at the Center for ADHD in Aarhus, Denmark; 2. Weekly one-hour training and discussion sessions with two psychologists working at the Center for ADHD for 25 weeks; 3.11 hours of observations in clinics with follow up interviews with child psychiatrists and psychologists; 4. Shadowing two psychologists during their observations of children being investigated for ADHD in school contexts for two full days; 5. Extensive classroom observations of children with ADHD $\left(2^{\text {nd }}-5^{\text {th }}\right.$ grade $)$ in addition to interviews with seven teachers from four different elementary schools and two pedagogues, who all had extensive experience working with children with ADHD; 6. Several ideation workshops with teachers, pedagogues and ADHD domain professionals; 7. Five hours of in the wild studies with 11 children with ADHD in $4^{\text {th }}-$ $5^{\text {th }}$ grade in three schools in order to evaluate a wearable system; 8. A four-week study with 13 children with ADHD and their families evaluating the effect of a mobile assistive technology to assist the families in establishing healthy morning and bedtime routines; and 9. An evaluation of a biofeedback game for children with ADHD at a summer camp. Therefore we have extensive experience in working with people who have ADHD and ADHD domain professionals in design assistive technologies.

\section{DESIGN FRAMEWORK: TECHNOLOGY AND ADHD CHALLENGES DIMENSIONS}

We now present our design framework for assistive technologies for the ADHD domain. The design framework consists of two dimensions as seen in Table 2. The technological dimension (the y-axis) relates to the question of how an assistive technology provides assistance. The 
ADHD dimension (the $\mathrm{x}$-axis) relates to the challenges and quality of life impairments associated with ADHD.

\section{The Technological Dimension}

The first approach in the technological dimension is manually interacted with information and services (MIIS), which covers technologies that are manually triggered or interacted with. The two MIIS subcategories further divide into technologies for assistance in context and technologies for training. The first subcategory covers systems that provide real time assistance in specific situations like TangiPlan (Weisberg et al., 2014), whereas the second subcategory relates to systems that aim to support a long term improvement in ADHD symptoms like CogoLand (Lim et al., 2012).

The second category automatically executing services based on in-situ analysis of context information (AES) comprises context aware technologies (cf. (Dey et al., 2001)) that analyze captured data and use this to provide insitu assistance to the user. Examples in the ADHD domain include ParentGuardian (Pina et al., 2014), CASTT (Sonne et al., 2015) and BlurtLine (Smit and Bakker, 2015).

The third category covers context aware technologies that capture contextual data for later retrieval $(C C D)$, but that do not automatically act on the users' behalf. We have divided this category into two subcategories based on whom the data is captured for: services for research and services for personal reflection.

\section{The ADHD Challenge Dimension}

In order to situate our design framework in the ADHD domain the ADHD dimension contains five general categories of challenges and impairments associated with ADHD taken from the Nature paper by (Faraone et al., 2015): 'Social disability', 'academic and occupational failure', 'health problems and psychiatric co-morbidities', 'psychological dysfunction', 'risky behaviors'. We introduced these categories in the 'Common Challenges for People with ADHD' section above.

\section{INVESTIGATING THE UNEXPLORED SPACE IN THE DESIGN FRAMEWORK}

Looking at the design framework in Table 2, we see that the $C C D$ category is the only category in the technological dimension that contains unexplored spaces, indicating a gap in the existing research on assistive technologies for the ADHD domain. However, assistive technologies for other patient groups suggest that CCD technologies do hold potential for assisting patients as illustrated below.

\begin{tabular}{|c|c|c|c|c|c|c|}
\hline \multirow{2}{*}{\multicolumn{2}{|c|}{ ADHD Challenge Dimension }} & $\begin{array}{c}\text { Social } \\
\text { disability }\end{array}$ & $\begin{array}{l}\text { Academic and } \\
\text { occupational } \\
\text { failure }\end{array}$ & $\begin{array}{c}\text { Health } \\
\text { problems and } \\
\text { psychiatric co- } \\
\text { morbidities }\end{array}$ & $\begin{array}{l}\text { Psychological } \\
\text { dysfunction }\end{array}$ & $\begin{array}{c}\text { Risky } \\
\text { behaviors }\end{array}$ \\
\hline & & $\begin{array}{l}\text { e.g., poor peer } \\
\text { and family } \\
\text { relationships, } \\
\text { poor social } \\
\text { skills. }\end{array}$ & $\begin{array}{c}\text { e.g., } \\
\text { underachievem } \\
\text { ent, special } \\
\text { education } \\
\text { needs. }\end{array}$ & $\begin{array}{c}\text { e.g., disruptive } \\
\text { behaviors, } \\
\text { executive } \\
\text { dysfunction, } \\
\text { sleep disorders. }\end{array}$ & $\begin{array}{l}\text { e.g., Emotional } \\
\text { dysregulation, } \\
\text { lack of } \\
\text { motivation. }\end{array}$ & $\begin{array}{c}\text { e.g., } \\
\text { accidents, } \\
\text { injuries, and } \\
\text { unplanned } \\
\text { pregnancies. }\end{array}$ \\
\hline $\begin{array}{c}\text { (MIIS) } \\
\text { Manually } \\
\text { interacting with }\end{array}$ & $\begin{array}{l}\text { Technologies } \\
\text { for in-situ } \\
\text { assistance in } \\
\text { context }\end{array}$ & MOBERO & TimeTimer & $\begin{array}{l}\text { MOBERO, } \\
\text { TangiPlan }\end{array}$ & ChillFish & \\
\hline $\begin{array}{c}\text { 1ntormation and } \\
\text { services }\end{array}$ & $\begin{array}{l}\text { Technologies } \\
\text { for training }\end{array}$ & ChillFish & CogMed & $\begin{array}{l}\text { CogMed, } \\
\text { CogoLand }\end{array}$ & ChillFish & \\
\hline $\begin{array}{c}\text { (AES) } \\
\text { Automatically } \\
\text { executing services } \\
\text { based on in-situ } \\
\text { analysis of context } \\
\text { information }\end{array}$ & & ParentGuardian & $\begin{array}{l}\text { CASTT, } \\
\text { SmartPen }\end{array}$ & $\begin{array}{l}\text { MOBERO, } \\
\text { BlurtLine }\end{array}$ & $\begin{array}{c}\text { Smart } \\
\text { wristband }\end{array}$ & \\
\hline $\begin{array}{c}(\boldsymbol{C C D}) \\
\text { Capturing } \\
\text { contextual data for } \\
\text { later retrieval }\end{array}$ & $\begin{array}{l}\text { Services for } \\
\text { research } \\
\text { Services for } \\
\text { personal } \\
\text { reflection }\end{array}$ & & & & & \\
\hline
\end{tabular}

Table 2: The design framework for assistive technologies for the ADHD domain. The ADHD challenge dimension relates to the quality of life impairments associated with ADHD. Existing assistive technologies are plotted in the design framework according to their categories. 
Examples of CCD Technologies from Related Domains MONARCA (Bardram et al., 2013) is an assistive technology designed for people with bipolar disorder and can be categorized as a $C C D$ system. MONARCA collects, analyzes, and presents subjective and objective data in order to provide bipolar patients and clinicians with insights into the parameters influencing the nature of the patient's disorder (Bardram et al., 2013). Thus, MONARCA would be placed in both of the $C C D$ sub-categories: services for research and services for personal reflection on the technological dimension in our design framework. In addition, many technologies within the domain of personal informatics can also be categorized within the $C C D$ category. For example, Lullaby (Kay et al., 2012) is a capture and access system that assists users in improving their sleep environment and includes a range of sensors including light, audio, motion, and temperature (Kay et al., 2012). Data from these sensors are visualized on a tablet, and support the user to learn about optimal conditions for their sleep. Furthermore, Lullaby provides users with the functionality to explore their recorded sleep and environmental data together with video recordings for further reflection about their sleep behaviors (Kay et al., 2012). Thus, Lullaby can also be categorized as a $C C D$ system (in the services for personal reflections subcategory) in our technology dimension.

Although we found no current $C C D$ technologies for the ADHD domain, we believe that this type of system holds significant potential. Capturing objective data from people with ADHD related to e.g., sleep, stress and mental wellbeing, could provide new insights into how these are related. This would allow scientists to develop new insights about ADHD based on detailed studies of large populations (similar to the StudentLife study (Wang et al., 2014), which analyzed how various contextual factors predicted GPA in a population of college students), and supporting individuals with ADHD in reflecting on and gaining insight into their own conditions - an approach that has been popularized in HCI as personal informatics (Li et al., 2010).

Based on the above investigation of the unexplored spaces within our design framework and the successful examples of $C C D$ systems in related domains, we encourage researchers to explore, design, and develop ADHD assistive technologies with $C C D$ functionality. Furthermore, looking at the unexplored spaces in the ADHD dimension, we see that no existing technologies are currently categorized within the "risky behaviors' category. We are not aware of existing technologies from other domains targeting risky behaviors, making such technologies truly unexplored. In the next section we describe how the design framework can be used to identify opportunities for future research within both explored and unexplored spaces.

USING THE DESIGN FRAMEWORK DIMENSIONS TO IDENTIFY OPPORTUNITIES FOR FUTURE RESEARCH

Below we will show how our design framework can be used to identify new opportunities for novel research on technologies for the ADHD domain by both advancing existing excellent research as well as establishing completely new technologies.

\section{Expanding Existing Research}

As the first example of how our design framework can be used to generate new research, we will look at BlurtLine (Smit and Bakker, 2015), which is categorized within the intersection of the AES and Health problems and psychiatric co-morbidities categories. The proposed design framework provides a visual overview of the opportunities for identifying new research directions for BlurtLine. For example, BlurtLine could be extended with the ability to capture data (e.g., time, date, school subject, location, current teacher, minutes into class etc.), analyze, and present these blurt data to teachers and/or researchers, which would then categorize BlurtLine as a $C C D$ system. This functionality could allow the child, parents and teachers to investigate if certain conditions trigger the impulsive speaking behavior, which could then be mitigating by the teacher. Thereafter, the effect of this change of actions could be evaluated by analyzing the captured sensor data providing an objective measure of the effect of the intervention.

CASTT is another example where the design framework could be used to identify future research directions. If CASTT was expanded with logging functionality to capture physical activity data from the individual, it could provide this data as a service for research, which could then be used by e.g., a child psychiatrist in the diagnostic process as a way to objectively quantify the hyperactivity in people with ADHD. Another opportunity for expanding the functionality of CASTT could be to look for patterns in how and when the child loses his concentration, and visualize these data for teachers, as a way for them to get feedback and reflect upon how e.g., different teaching techniques or methods affect the child with ADHD. In this way, CASTT would be categorized within the services for personal reflection subcategory of the $C C D$ category.

Having highlighted how our design framework could be used to provide new directions for two existing research technologies, we now illustrate how it can also be used to generate ideas for new research projects, by using an example of our own ongoing research on assistive technologies for the ADHD domain.

\section{Creating New Research Approaches}

As presented, children with ADHD have significantly higher bedtime resistance, sleep onset difficulties, and sleep disordered breathing compared to children without ADHD (Cortese et al., 2009). These challenges are related to the Health problems and psychiatric co-morbidities category in the design framework. From the existing technologies plotted in the design framework we see that there is an unexplored space for $C C D$ technologies in the Health problems and psychiatric co-morbidities category. Having decided on the domain and type of technology, a design 
process with health professionals and users was initiated. Based on our interdisciplinary design process and inspired by existing work within the ADHD domain (Sonne et al., 2016b), related work on sleep technologies (Choe et al., 2011; Kay et al., 2012), and research on sleep (Cortese et al., 2009), we created a vision for a future research project called SleepAssist to extend the MOBERO project. SleepAssist can be categorized as a technology that provides services for personal reflection within the $C C D$ category. SleepAssist should utilize a sleep sensor placed under the child's mattress to capture information about the child's sleep habits. If SleepAssist detects that the child's bedtime varies too much throughout a week, the parents would be notified about this unhealthy habit together with information about the potential implications of this behavior i.e., increased inattention, disruptive behavior, and decreased executive functioning (Cortese et al., 2009). Moreover, SleepAssist suggests to parents how to improve their child's sleep habits. In addition to provide services for personal reflection, SleepAssist could also provide services for research: the sleep data could be shared with e.g., a child psychiatrist. In Denmark and many other countries, a child psychiatrist has to investigate if poor sleep habits could be the root cause of a child's behavior, as part of the ADHD investigation. This process involves asking parents to complete a sleep diary. However, as we have previously reported, the accuracy of such sleep diaries can be doubted (Sonne et al., 2016b). Thus, a technology that captures objective sleep data could hold the potential to be a supplement to the existing diagnostic process. Similarly, using a sleep monitoring system prior to and after medication might also provide medical researchers with new insights into the effects of ADHD medication on sleep.

Furthermore, from the framework we see that no technologies exist within the assistive technology literature that specifically target "risky behaviors" for people with ADHD. There is therefore an opportunity for researchers to target these behaviors: for example, a $C C D$ system for personal reflection might help someone with ADHD to identify behavior patterns that lead to injuries and to take steps to mitigate them, or an $A E S$ system might analyze contextual factors to give someone with ADHD a warning.

In this section, we have shown how the design framework can be used to expand the functionality of existing assistive technologies for the ADHD domain, and we have also provided an example from our own ongoing research on how the design framework can be used early in a design process to guide the development of novel research on assistive technologies for the ADHD domain.

\section{The Design Framework is an Open Design Space}

Having filled the design framework in Table 2 with examples of existing work may give a misleading impression of no need for novelty in designing assistive technologies for areas of the design framework where research already exists. However, the examples CASTT
(Sonne et al., 2015) and SmartPen (DePrenger et al., 2010) are only example of $A E S$ technologies within the academic and occupational failure category. Thus there is still an open design space for further research on assistive technologies in this area. The five categories in the ADHD dimension are broad, and as more assistive technologies for the ADHD domain are being developed, it might make sense to create separate sub-categories for the categories in the ADHD dimension related to the specific challenges and impairments people with ADHD experience. Nevertheless, we think that the current "level of detail" in the design framework can provide HCI researchers with a starting point for designing assistive technologies and it also enables a way to discuss and categorize assistive technologies for the ADHD domain.

\section{DESIGN FRAMEWORK: STRATEGIES FOR $\mathrm{HCI}$ RESEARCH WITHIN THE ADHD DOMAIN}

We have presented our design framework and shown how it can be used to identify new research directions for assistive technologies for the ADHD domain. The HCI field lacks design strategies that support researchers in transitioning from the theory/idea phase to successfully develop and deploy assistive technologies for the ADHD domain. In this section we present practical design strategies for developing assistive technologies for the ADHD domain that are inspired by research on ADHD, our own empirical studies, and existing practices that people with ADHD, ADHD professionals, and teachers use to limit and cope with some of the common challenges that people with ADHD experience. Finally, we discuss strategies for maximizing the impact of research on ADHD assistive technologies.

\section{Provide Structure to Facilitate Activities}

Structure is beneficial for people with ADHD, as they are more likely to succeed in completing tasks if they occur in a predictable pattern. Empirical studies of families with children with ADHD found routines and structure to be the most important factor in supporting daily family life (Firmin and Phillips, 2009). Furthermore, a core element in parent training is to organize and structure the child's day as this reduces the chances of tensions. One of the most common existing practices to assist in establishing healthy routines is to use printed charts or checklists, which the person with ADHD can rely on to complete specific routines. However, parents of children with ADHD can experience two key challenges that make it hard for them to provide the needed structure. First, due to the high heritability of ADHD, the parents might themselves experience challenges in creating and providing the needed structure (Firmin and Phillips, 2009). Second, paper-based chart often do not motivate the child and are easily mislaid, damaged and forgotten, resulting in an abandoning of the chart-based system (Sonne et al., 2016b).

\section{Minimize Distractions}

Attention deficit is one of the core characteristics of ADHD. Thus, it is beneficial to limit external distractions in order to prevent people with ADHD from losing attention. 
In school, extra work is done to limit distractions in order to assist the child in staying focused on school tasks, such as seating the child in the front of the class or providing head to reduce distracting sounds in appropriate situations. This poses a challenge for researchers, as technology itself can be seen as a distraction for the child. Care should therefore be taken in any technological intervention to avoid unnecessary distractions. For instance, when sleep assistance such as MOBERO (Sonne et al., 2016b) introduces technology just before bedtime, it needs to be carefully investigated for potential distraction effects.

\section{Encourage Praise and Rewards}

Praising and rewarding a child or a teenager with ADHD is a core element in parent training as this promotes desired behaviors (National Collaborating Centre for Mental Health (Great Britain) and NCCMH, 2013). Often parents and teachers use a chart based system where the child collects stars or stickers for performing certain activities (e.g. brushing teeth) or behaving in a certain way that the parents or teachers want to encourage (e.g. do not yell at the teacher or other pupils during class) (Sonne and Grønbæk, 2015). However, as parents of children with ADHD experience increased levels of stress (Harpin, 2005), they can find it challenging to remember to praise and reward their child (Pina et al., 2014). Furthermore, as children with ADHD are often very reward driven (Sonne and Grønbæk, 2015), researchers can use and explore opportunities for using rewards in assistive technologies as a way to encourage children to perform certain activities or behavior, e.g., Sonne et al. reported that rewards were an important and deliberate part of their design (Sonne et al., 2016b).

\section{Integrate and Report Standardized ADHD measures}

An important factor to maximize the impact of research on ADHD assistive technologies is to include relevant measures in the study design and report these in an appropriate way. A similar discussion has recently been started within the ASD assistive technology community (Carter and Hyde, 2015), and here we briefly discuss key factors that are relevant to integrate and report in studies with people with ADHD in order to maximize the impact of the conducted research.

First, we propose that researchers should assess and report standardized scores of the severity of ADHD symptoms. This is critical as: 1 . it ensures that the patients in the study are representative of the general population of patients with ADHD; 2. it provides transparency; 3. such standardized measures are already used within the existing medical and physiological domains (both as inclusion criteria and efficacy of treatment); and 4. it allows researchers to evaluate the size of the effect associated with using their technology, based on a standardized scale. This also provides opportunities for comparison to traditional treatments and (future) technology based interventions.

Within HCI research, only Pina et al. report that they used a standardized rating scale (though only used as an inclusion criterion) (Pina et al., 2014). Pina et al. report that they lowered the cut-off values "for the sake of the exploratory study" (Pina et al., 2014), however critically failed to report how many of their participants actually had an ADHD score within the normal ADHD range. This missing information makes it impossible for the reader to judge if the ParentGuardian system was evaluated with children with ADHD, or children with mild ADHD-like symptoms.

Second, we argue that it is important to report whether the participants receive any medical treatment during the evaluation due to the natural effects of these treatments (e.g. lowering ADHD symptoms), which could confound any effects attributable to the intervention. To date only the work on TangiPlan has mentioned this issue (Weisberg et al., 2014). In particular, children who receive changes to their dose of medication shortly before or during an evaluation period, should be excluded from the study, as adjusting the dose can have several side effects that might affect the evaluation of an assistive technology.

Finally, we agree with Klasnja et al.'s (2011) argument that evaluations of novel technologies which focus mostly on qualitative findings are fundamental, especially as this field of assistive technologies for the ADHD domain is still in its infancy. Gaining insights into setting up studies, unexpected outcomes, unique challenges etc. are critical for informing credible research. The HCI community is a natural context for interdisciplinary research teams to explore and report promising technologies for the ADHD domain that can later be followed up with randomized controlled trials. Thus, it is both important to focus on qualitative findings that can bring the field forwards, but also to include quantitative (standardized) measures so that these novel technologies can be taken to the next stage in the medical evaluation.

\section{CONCLUSION}

We have presented a design framework for ADHD assistive technology that is solidly grounded in empirical studies, ADHD research, and related work on assistive technologies. The framework consists of: 1) conceptual dimensions to couple technologies to ADHD challenges, and 2) a set of practical design strategies for developing successful assistive technologies for people with ADHD. The design framework gives researchers grounding in the condition, provides a lingua franca, and highlights unexplored research directions within assistive technologies for the ADHD domain. By mapping existing and potential new research to the design framework, we have demonstrated how it can be used to support and advance the research and development of novel assistive technologies for the ADHD domain. 


\section{REFERENCES}

Abdullah, M.H.L., Brereton, M., 2015. MyCalendar: Fostering Communication for Children with Autism Spectrum Disorder Through Photos and Videos, in: Proceedings of the Annual Meeting of the Australian Special Interest Group for Computer Human Interaction, OzCHI '15. ACM, New York, NY, USA, pp. 1-9. doi: $10.1145 / 2838739.2838785$

Attention deficit hyperactivity disorder | Guidance and guidelines | NICE [WWW Document], 2015. URL http:/www.nice.org.uk/guidance/cg72/chapter/introduct ion (accessed 12.10.15).

Bardram, J.E., Frost, M., Szántó, K., Faurholt-Jepsen, M., Vinberg, M., Kessing, L.V., 2013. Designing Mobile Health Technology for Bipolar Disorder: A Field Trial of the Monarca System, in: Proceedings of the SIGCHI Conference on Human Factors in Computing Systems, CHI '13. ACM, New York, NY, USA, pp. 2627-2636. doi:10.1145/2470654.2481364

Biederman, J., Faraone, S.V., 2005. Attention-deficit hyperactivity disorder. The Lancet 366, 237-248. doi:10.1016/S0140-6736(05)66915-2

Carter, E.J., Hyde, J., 2015. Designing Autism Research for Maximum Impact, in: Proceedings of the 33rd Annual ACM Conference on Human Factors in Computing Systems, CHI '15. ACM, New York, NY, USA, pp. 2801-2804. doi:10.1145/2702123.2702471

Chacko, A., Kofler, M., Jarrett, M., 2014. Improving Outcomes for Youth with ADHD: A Conceptual Framework for Combined Neurocognitive and SkillBased Treatment Approaches. Clin. Child Fam. Psychol. Rev. 17, 368-384. doi:10.1007/s10567-0140171-5

Choe, E.K., Consolvo, S., Watson, N.F., Kientz, J.A., 2011. Opportunities for Computing Technologies to Support Healthy Sleep Behaviors, in: Proceedings of the SIGCHI Conference on Human Factors in Computing Systems, CHI '11. ACM, New York, NY, USA, pp. 3053-3062. doi:10.1145/1978942.1979395

Cogmed Working Memory Training [WWW Document], 2015. URL http://www.cogmed.com/ (accessed 1.1.15).

Cortese, S., Faraone, S.V., Konofal, E., Lecendreux, M., 2009. Sleep in Children With AttentionDeficit/Hyperactivity Disorder: Meta-Analysis of Subjective and Objective Studies. J. Am. Acad. Child Adolesc. Psychiatry 48, 894-908. doi:10.1097/CHI.0b013e3181ac09c9

Cramer, M., Hirano, S.H., Tentori, M., Yeganyan, M.T., Hayes, G.R., 2011. Classroom-based Assistive Technology: Collective Use of Interactive Visual Schedules by Students with Autism, in: Proceedings of the SIGCHI Conference on Human Factors in Computing Systems, CHI '11. ACM, New York, NY, USA, pp. 1-10. doi:10.1145/1978942.1978944
Dalsgaard, S., Mortensen, P.B., Frydenberg, M., Thomsen, P.H., 2013. Long-term criminal outcome of children with attention deficit hyperactivity disorder. Crim. Behav. Ment. Health CBMH 23, 86-98. doi:10.1002/cbm.1860

DePrenger, M., Shao, Y., Lu, F., Fleming, N., Sikdar, S., 2010. Feasibility study of a smart pen for autonomous detection of concentration lapses during reading. Eng. Med. Biol. Soc. EMBC 2010, 1864-1867. doi:10.1109/IEMBS.2010.5626256

Dey, A.K., Abowd, G.D., Salber, D., 2001. A Conceptual Framework and a Toolkit for Supporting the Rapid Prototyping of Context-aware Applications. HumComput Interact 16, 97-166. doi:10.1207/S15327051HCI16234_02

Diagnostic and Statistical Manual of Mental Disorders: Fifth Edition: DSM-5, 2013. . American Psychiatric Pub.

Fage, C., Pommereau, L., Consel, C., Balland, É., Sauzéon, H., 2014. Tablet-based Activity Schedule for Children with Autism in Mainstream Environment, in: Proceedings of the 16th International ACM SIGACCESS Conference on Computers \& Accessibility, ASSETS '14. ACM, New York, NY, USA, pp. 145-152. doi:10.1145/2661334.2661369

Faraone, S.V., Asherson, P., Banaschewski, T., Biederman, J., Buitelaar, J.K., Ramos-Quiroga, J.A., Rohde, L.A., Sonuga-Barke, E.J.S., Tannock, R., Franke, B., 2015. Attention-deficit/hyperactivity disorder. Nat. Rev. Dis. Primer 15020.

Firmin, M.W., Phillips, A., 2009. A Qualitative Study of Families and Children Possessing Diagnoses of ADHD. J. Fam. Issues 30, 1155-1174. doi:10.1177/0192513X09333709

Harpin, V.A., 2005. The effect of ADHD on the life of an individual, their family, and community from preschool to adult life. Arch. Dis. Child. 90 Suppl 1, i2-7. doi:10.1136/adc.2004.059006

Hirano, S.H., Yeganyan, M.T., Marcu, G., Nguyen, D.H., Boyd, L.A., Hayes, G.R., 2010. vSked: Evaluation of a System to Support Classroom Activities for Children with Autism, in: Proceedings of the SIGCHI Conference on Human Factors in Computing Systems, CHI '10. ACM, New York, NY, USA, pp. 1633-1642. doi:10.1145/1753326.1753569

Kay, M., Choe, E.K., Shepherd, J., Greenstein, B., Watson, N., Consolvo, S., Kientz, J.A., 2012. Lullaby: A Capture \& Access System for Understanding the Sleep Environment, in: Proceedings of the 2012 ACM Conference on Ubiquitous Computing, UbiComp '12. ACM, New York, NY, USA, pp. 226-234. doi:10.1145/2370216.2370253 
Kientz, J.A., Goodwin, M.S., Hayes, G.R., Abowd, G.D., 2013. Interactive Technologies for Autism. Synth. Lect. Assist. Rehabil. Health-Preserv. Technol. 2, 1-177. doi:10.2200/S00533ED1V01Y201309ARH004

Klasnja, P., Consolvo, S., Pratt, W., 2011. How to Evaluate Technologies for Health Behavior Change in HCI Research, in: Proceedings of the SIGCHI Conference on Human Factors in Computing Systems, CHI '11. ACM, New York, NY, USA, pp. 3063-3072. doi:10.1145/1978942.1979396

Li, I., Dey, A., Forlizzi, J., 2010. A Stage-based Model of Personal Informatics Systems, in: Proceedings of the SIGCHI Conference on Human Factors in Computing Systems, CHI '10. ACM, New York, NY, USA, pp. 557-566. doi:10.1145/1753326.1753409

Lim, C.G., Lee, T.S., Guan, C., Fung, D.S.S., Zhao, Y., Teng, S.S.W., Zhang, H., Krishnan, K.R.R., 2012. A Brain-Computer Interface Based Attention Training Program for Treating Attention Deficit Hyperactivity Disorder. PLoS ONE 7, e46692. doi:10.1371/journal.pone.0046692

Massetti, G.M., Lahey, B.B., Pelham, W.E., Loney, J., Ehrhardt, A., Lee, S.S., Kipp, H., 2008. Academic achievement over 8 years among children who met modified criteria for attention-deficit/hyperactivity disorder at 4-6 years of age. J. Abnorm. Child Psychol. 36, 399-410. doi:10.1007/s10802-007-9186-4

McHugh, B., Dawson, N., Scrafton, A., Asen, E., 2010. "Hearts on their sleeves": the use of systemic biofeedback in school settings. J. Fam. Ther. 32, 58-72. doi:10.1111/j.1467-6427.2009.00486.x

Milne, L.R., Bennett, C.L., Ladner, R.E., Azenkot, S., 2014. BraillePlay: Educational Smartphone Games for Blind Children, in: Proceedings of the 16th International ACM SIGACCESS Conference on Computers \& Accessibility, ASSETS '14. ACM, New York, NY, USA, pp. 137-144. doi:10.1145/2661334.2661377

National Collaborating Centre for Mental Health (Great Britain), NCCMH, 2013. Antisocial behaviour and conduct disorders in children and young people: recognition, intervention and management2. RCPsych Publications.

Perou, R., Bitsko, R.H., Blumberg, S.J., Pastor, P., Ghandour, R.M., Gfroerer, J.C., Hedden, S.L., Crosby, A.E., Visser, S.N., Schieve, L.A., 2013. Mental health surveillance among children-United States, 20052011. MMWR Surveill Summ 62, 1-35.

Pina, L., Rowan, K., Roseway, A., Johns, P., Hayes, G.R., Czerwinski, M., 2014. In Situ Cues for ADHD Parenting Strategies Using Mobile Technology, in: Proceedings of the 8th International Conference on Pervasive Computing Technologies for Healthcare, PervasiveHealth '14. ICST (Institute for Computer Sciences, Social-Informatics and Telecommunications
Engineering), ICST, Brussels, Belgium, Belgium, pp. 17-24. doi:10.4108/icst.pervasivehealth.2014.254958

Shaw, P., Stringaris, A., Nigg, J., Leibenluft, E., 2014. Emotion Dysregulation in Attention Deficit Hyperactivity Disorder. Am. J. Psychiatry 171, 276293. doi:10.1176/appi.ajp.2013.13070966

Smit, D., Bakker, S., 2015. BlurtLine: A Design Exploration to Support Children with ADHD in Classrooms, in: Abascal, J., Barbosa, S., Fetter, M., Gross, T., Palanque, P., Winckler, M. (Eds.), HumanComputer Interaction - INTERACT 2015, Lecture Notes in Computer Science. Springer International Publishing, pp. 456-460.

Sonne, T., Grønbæk, K., 2015. Designing Assistive Technologies for the ADHD Domain, in: Serino, S., Matic, A., Giakoumis, D., Lopez, G., Cipresso, P. (Eds.), Pervasive Computing Paradigms for Mental Health, Communications in Computer and Information Science. Springer International Publishing, pp. 259-268. doi:10.1007/978-3-319-32270-4_26

Sonne, T., Jensen, M.M., 2016a. ChillFish: A Respiration Game for Children with ADHD, in: Proceedings of the TEI '16: Tenth International Conference on Tangible, Embedded, and Embodied Interaction, TEI '16. ACM, New York, NY, USA, pp. 271-278. doi: $10.1145 / 2839462.2839480$

Sonne, T., Jensen, M.M., 2016b. Evaluating the ChillFish Biofeedback Game with Children with ADHD, in: Proceedings of the The 15th International Conference on Interaction Design and Children, IDC '16. ACM, New York, NY, USA, pp. 529-534. doi:10.1145/2930674.2935981

Sonne, T., Marshall, P., Müller, J., Obel, C., Grønbæk, K., 2016a. A Follow-up Study of a Successful Assistive Technology for Children with ADHD and Their Families, in: Proceedings of The 15th International Conference on Interaction Design and Children, IDC '16. ACM, New York, NY, USA, pp. 400-407. doi:10.1145/2930674.2930704

Sonne, T., Müller, J., Marshall, P., Obel, C., Grønbæk, K., 2016b. Changing Family Practices with Assistive Technology: MOBERO Improves Morning and Bedtime Routines for Children with ADHD, in: Proceedings of the 34th Annual ACM Conference on Human Factors in Computing Systems, CHI '16. ACM, New York, NY, USA. doi:10.1145/2858036.2858157

Sonne, T., Obel, C., Grønbæk, K., 2015. Designing Real Time Assistive Technologies: A Study of Children with ADHD, in: Proceedings of the Annual Meeting of the Australian Special Interest Group for Computer Human Interaction, OzCHI '15. ACM, New York, NY, USA, pp. 34-38. doi:10.1145/2838739.2838815

Storebø, O.J., Ramstad, E., Krogh, H.B., Nilausen, T.D., Skoog, M., Holmskov, M., Rosendal, S., Groth, C., 
Magnusson, F.L., Moreira-Maia, C.R., Gillies, D., Buch Rasmussen, K., Gauci, D., Zwi, M., Kirubakaran, R., Forsbøl, B., Simonsen, E., Gluud, C., 2015. Methylphenidate for children and adolescents with attention deficit hyperactivity disorder (ADHD), in: Cochrane Database of Systematic Reviews. John Wiley \& Sons, Ltd.

Storebø, O.J., Skoog, M., Rasmussen, P.D., Winkel, P., Gluud, C., Pedersen, J., Thomsen, P.H., Simonsen, E., 2014. Attachment Competences in Children With ADHD During the Social-Skills Training and Attachment (SOSTRA) Randomized Clinical Trial. J. Atten. Disord. 1087054713520220. doi: $10.1177 / 1087054713520220$

Time Timer [WWW Document], 2016. URL http://www.timetimer.com (accessed 4.4.16).

Wang, R., Chen, F., Chen, Z., Li, T., Harari, G., Tignor, S., Zhou, X., Ben-Zeev, D., Campbell, A.T., 2014. StudentLife: Assessing Mental Health, Academic Performance and Behavioral Trends of College Students Using Smartphones, in: Proceedings of the 2014 ACM International Joint Conference on Pervasive and Ubiquitous Computing, UbiComp '14. ACM, New York, NY, USA, pp. 3-14. doi:10.1145/2632048.2632054
Webster-Stratton, C., Jamila, M., 2003. The incredible years parents, teachers and children training series: A multifaceted treatment approach for young children with conduct problems, in: Kazdin, A.E., Weisz, J.R. (Eds.), Evidence-Based Psychotherapies for Children and Adolescents. Guilford Press, New York, NY, US, pp. 224-240.

Wehmeier, P.M., Schacht, A., Barkley, R.A., 2010. Social and Emotional Impairment in Children and Adolescents with ADHD and the Impact on Quality of Life. J. Adolesc. Health 46, 209-217. doi:10.1016/j.jadohealth.2009.09.009

Weisberg, O., GalOz, A., Berkowitz, R., Weiss, N., Peretz, O., Azoulai, S., KoplemanRubin, D., Zuckerman, O., 2014. TangiPlan: Designing an Assistive Technology to Enhance Executive Functioning Among Children with Adhd, in: Proceedings of the 2014 Conference on Interaction Design and Children, IDC '14. ACM, New York, NY, USA, pp. 293-296. doi:10.1145/2593968.2610475

World Health Organization, 1992. The ICD-10 classification of mental and behavioural disorders: clinical descriptions and diagnostic guidelines. Geneva : World Health Organization. 